\title{
Harvested fish stocks in a changing environment
}

\author{
Editors: J. M. Durant, N. C. Stenseth \\ Marine Ecology Progress Series Vol. 480, pages 199-287
}

\section{CONTENTS}

Durant JM, Ottersen G, Stenseth NC INTRODUCTION: Impact of climate and fisheries on sub-Arctic stocks ...

$199-203$

Ottersen G, Stige LC, Durant JM, Chan KS, Rouyer TA, Drinkwater KF, Stenseth NC

Temporal shifts in recruitment dynamics of

North Atlantic fish stocks: effects of spawning

stock and temperature

Ciannelli L, Fisher JAD, Skern-Mauritzen M, Hunsicker ME, Hidalgo M, Frank KT, Bailey KM Theory, consequences and evidence of eroding population spatial structure in harvested marine fishes: a review

$227-243$
Stige LC, Hunsicker ME, Bailey KM,

Yaragina NA, Hunt GL Jr

Predicting fish recruitment from juvenile

abundance and environmental indices $245-261$

Hjermann DØ, Fisher JAD, Rouyer T, Frank KT, Stenseth NC

Spatial analysis of North Sea cod recruitment: concurrent effects of changes in spawning stock biomass, temperature and herring abundance... 263-275

Durant JM, Hidalgo M, Rouyer T,

Hjermann DØ, Ciannelli L, Eikeset AM, Yaragina N, Stenseth NC

Population growth across heterogeneous environ-

\section{INTRODUCTION}

\section{Impact of climate and fisheries on sub-Arctic stocks}

\author{
Joël M. Durant ${ }^{1, *}$, Geir Ottersen ${ }^{1,2}$, Nils C. Stenseth ${ }^{1,3}$ \\ ${ }^{1}$ Centre for Ecological and Evolutionary Synthesis (CEES), Department of Biosciences, University of Oslo, \\ PO Box 1066 Blindern, 0316 Oslo, Norway \\ ${ }^{2}$ Institute of Marine Research, PO Box 1870 Nordnes, 5817 Bergen, Norway \\ ${ }^{3}$ Institute of Marine Research, Flødevigen Marine Research Station, 4817 His, Norway
}

\begin{abstract}
Understanding the drivers (internal and external) that determine the productivity of marine ecosystems is challenging. For example, the correct estimate of recruitment is essential to estimate fish stock abundance. In this Theme Section, 5 papers explore the effect of fishing and climate on population structure across sub-Arctic ecosystems. The studies focus on how temperatureand fishing-induced changes in spatial and demographic population structure affect recruitment and population growth rate. The results suggest common patterns, but also highlight differences in the relative importance of fishing and climate among the populations and ecosystems examined.
\end{abstract}

KEY WORDS: Climate $\cdot$ Non-stationarity $\cdot$ Spatial distribution $\cdot$ Recruitment $\cdot$ Population growth Sub-Arctic 


\section{Introduction}

There is growing awareness among fisheries scientists that climate variability and fisheries influence the state and functioning of marine ecosystems. Importantly, the effects of climate and exploitation interact, such that climate alterations may cause failure in a fishery management scheme, while fisheries may disrupt the ability of a population to withstand, or adjust to, climate change (Planque et al. 2010). Accordingly, marine ecosystems under intense exploitation may evolve towards stronger bottom-up control and greater sensitivity to climate forcing (Perry et al. 2010). Because climate change occurs slowly, its effects are not likely to have immediate ecosystem impacts, but will gradually become evident by affecting the interactions between fishing and environmental variability.

To explore this topic - with a focus on comparative analyses of sub-Arctic seas - two international workshops were hosted by the Centre for Ecology and Evolutionary Synthesis (CEES) of the University of Oslo in November 2009 and March 2011. The workshops brought together scientists from 5 countries (Canada, France, Norway, Russia and the USA) with expertise in theoretical ecology, animal behaviour, fish ecology, fisheries oceanography and ecosystem modelling. This Theme Section is composed of 5 papers that resulted from the workshops and the surrounding discussions.

There is no a priori reason to assume that fish populations, let alone ecosystems, display a linear response to the joint pressure from climate and exploitation. Thus, the methods employed to study such effects should be able to deal with nonadditive and non-linear patterns. Moreover, the relationship between recruitment, spawning stock biomass and temperature frequently varies over time, so temporal non-stationarity should also generally be taken into consideration when analysing fish stock data. Besides temporal non-stationarity, spatial non-stationarity may also affect population dynamics. For instance, the non-uniform fishing pressure on population sub-units may lead to a reduction in the capacity of populations to withstand climate variability and change. In addition, since small, pelagic forage fish often prey on the egg and juvenile stages of their larger fish predators, selective fishing of either the top predators or the pelagic forage fish component of the system may lead to a role-reversal and destabilize the ecosystem (Bakun 2010, Fauchald 2010).
This Theme Section provides substantial insights into how environmental variability and fisheries affect population dynamics of harvested marine fish stocks. Each paper addresses one of 5 key points, as detailed in the following sections.

\section{(1) Temporal shifts in and temperature effects on recruitment dynamics}

Density-independent environmental factors are assumed to be of primary importance in regulating the size of fish populations, accounting for most of the variability in pre-juvenile survival (Houde 2008). On the other hand, density-dependent survival in the juvenile phase is also considered to be a key factor and is embodied in many age structured fisheries assessment models where regulation is effected through a stock-recruitment relationship (Hilborn \& Walters 1992). Thus, disentangling the effects of climate variability and internal population dynamics on recruitment remains a challenge.

In the first paper in this Theme Section, Ottersen et al. (2013) tested, by means of statistical modelling, 7 hypotheses relating variation in sea temperature, spawning stock biomass, and mean age in the spawning stock to temporal patterns in recruitment dynamics of 38 commercially harvested North Atlantic fish stocks. Their results highlight the need to be careful not to over-interpret purely linear environmentrecruitment associations (like correlations), since the underlying relations may be non-linear and variable over time. The reason for established correlations to break down when new data are added may be nonstationarity, i.e. recruitment dynamics undergoing temporal shifts. Ottersen et al. (2013) found that nonstationarities in recruitment dynamics are quite frequent and often abrupt. The most frequent alteration in the non-stationary linear models occurred in the intercept in recruitment success, suggesting a change in pre-recruit mortality over time (observed for 14 stocks).

\section{(2) Erosion of population spatial structure}

All animal populations are spatially structured as a result of the physical environment and of behavioural and biological processes occurring within and between different populations. Changes in the spatial structure of marine populations can be a prelude to further changes in abundance and can affect the resilience of a population to human and environmental perturbations. There is evidence that large varia- 
tions in species abundance over time are typically accompanied by equally dramatic and large-scale changes in spatial distribution patterns, not only for marine fishes but for animal populations in general (e.g. Gaston et al. 2000, Bacheler et al. 2009). Moreover, changing spatial patterns can subject individuals to a set of new environmental constraints and interspecific interactions, and can have consequences at the community level.

Ciannelli et al. (2013, this Theme Section) underscore the importance of examining the spatial ecology of fish populations to (1) understand the underlying mechanisms that can lead to rapid alterations in population abundance and community interactions, (2) provide indicators of stock health, and (3) characterize the consequences of changing spatial patterns on the population susceptibility to human exploitation and environmental variability. In their review, Ciannelli et al. (2013) have shown how populations can be spatially structured, regardless of their genetic and demographic connections, and that the erosion of such spatial structure has negative consequences at the population and community levels.

\section{(3) Predicting fish recruitment}

Prediction of year-class strength is a critical challenge for fisheries managers. Spawning stock biomass (SSB) may be a useful predictor of future recruitment at extreme high or low values, but there is enormous variability in the relationship between SSB and recruitment strength at intermediate values of SSB. This lack of relationship indicates that other, environmental, variables are likely to play an important role in determining the production of recruits. In particular, the survival of egg and larval stages are vulnerable to any number of catastrophic impacts from the environment, whereas the survival of juveniles may be more predictable.

Stige et al. (2013, this Theme Section) examined the usefulness of juvenile relative to larval abundance in predicting recruitment. They analysed data on 5 marine fish stocks covering 4 species and 3 Arctic ecosystems. They found that abundance indices of later life stages do not always provide better estimates than those based on earlier life stages, and suggest that this unexpected result was due to the poor quality of the time series collected for older life stages. Stige et al. (2013) showed that the inclusion of environmental indices often improved the accuracy of 'honest' predictions of recruitment, i.e. predictions based upon data not used when fitting the recruitment models. Stige et al.
(2013) finally stressed that even with complex marine systems, the environment-recruitment correlations were found to be unstable, and the available timeseries were short, consideration of environmental information may still improve recruitment predictions.

\section{(4) Predator-prey interaction}

Unlike most terrestrial ecosystems, marine systems may allow for role-reversal between prey and predators. Small, pelagic forage fish are often themselves predators of, and competitors with, the egg and juvenile stages of their larger fish predators. In fact, prey species may flourish as a result of decreased predation pressure when predatory fish have been fished down (e.g. Frank et al. 2011). Subsequently, they may prevent the recovery of the predator, e.g. by preying on the predator's eggs and larvae (Bakun \& Weeks 2006, Bakun 2010). Thus a large population of forage fish may reduce the recruitment of predators to the extent that the system switches to an alternate prey-dominated state. Consequently, selective human harvesting of either the predators or the forage fish may cause ecosystem shifts by 'pushing' the system between the respective states (Bakun 2010, Fauchald 2010).

Hjermann et al. (2013, this Theme Section) scrutinized the potential predator-prey reversal scenario for the North Sea suggested by Fauchald (2010) by conducting a spatially resolved analysis based upon $40 \mathrm{yr}$ of cod and herring Clupea harengus data. They found that the mechanisms for the changes in cod and herring abundance vary spatially throughout the North Sea. For instance, the largest decline in cod recruitment occurred along the coasts of the Netherlands, Germany and Denmark, where herring abundance and water temperature have increased more than in other parts of the North Sea. In this area, the cod and herring were oppositely affected by the observed increase in sea surface temperatures (the cod negatively, the herring positively), and herring abundance had an additional negative effect on cod recruitment. Thus, for parts of the southern North Sea, the findings of Hjermann et al. (2013) are consistent with the hypothesis of alternative stable states, while for other parts there is no evidence that such mechanisms operate.

\section{(5) Population growth rate across heterogeneous environments}

Population growth is affected by several factors such as climate, species interactions, and harvesting 
pressure, with the latter making marine populations more sensitive to climate forcing (Hsieh et al. 2010). Age-truncated or juvenescent populations are a worldwide consequence of high and often sizeselective mortality from commercial fishing, typically targeting the older and larger individuals (Law 2000). Juvenation may increase a populations' ability to directly respond to environmental fluctuations (Rouyer et al. 2011), emphasizing the importance of the interaction between fisheries, environment, and recruitment and population growth that produces complex synergic effects on the population dynamics of marine species.

Durant et al. (2013, this Theme Section) explored how external forcing (climate and fishing) and recruitment modulate the population dynamics of fish within different environments. They calculated the realized yearly population growth rate of 7 gadoid stocks across different ecosystems. By comparing the corresponding sensitivity of population growth to recruitment change across the 7 stocks, Durant et al. (2013) showed that reduction in generation time triggered an increase in the relative contribution of recruitment to population growth, while the increase of fishing mortality - suggested to truncate the age structure of the stocks - had a weaker effect. The findings of Durant et al. (2013) emphasise how the elasticity of the population growth to recruitment change can be affected by a long-term change in age structure of the population, maybe due to fishing (e.g. Rouyer et al. 2011, but see Ottersen et al. 2013), but also directly by the ongoing fishing intensity.

\section{Conclusions}

The key message of this Theme Section is the importance of the interplay between environment and stock (size and structure) in shaping recruitment of sub-Arctic marine fish stocks. The 5 papers highlight different aspects of this theme and draw attention to the value of monitoring temporal and spatial patterns, as well as environmental forcing. In this Theme Section, we have demonstrated that:

(1) Recruitment estimates may be improved by taking into account environmental information and non-stationarity. Ottersen et al. (2013) showed that temperature may affect the stock-recruitment relation and that the effect can change through time, also abruptly. The situation is further complicated by the temperature-recruitment relation also displaying spatial differences within the same sea (Hjermann et al. 2013). Still, Stige et al. (2013) showed that envi- ronmental information can aid the prediction of recruitment. Furthermore, while much of the year class strength is determined during egg and larval stages, this pattern may be overshadowed by density-dependent mortality factors operating at later life stages (Stige et al. 2013). Later measures, closer to recruitment, should thus be the better recruitment predictors. However, Stige et al. (2013) did not find such a consistent improvement, perhaps due to the shortness of the available time series.

(2) Age-structure may be important for understanding the dynamics of harvested populations. Durant et al. (2013) showed that the contribution of recruitment to population growth was affected by environmental conditions and by the age-structure of the population. However, contrary to what was expected, Ottersen et al. (2013) found little or no general decrease in mean age in the spawning stock. Still, results shown at our second workshop demonstrate remarkable decreases in the number of reproductive age groups in 6 NW Atlantic cod stocks, in the most extreme case from 12 to 4 groups (K. Frank, pers. comm.). The lack of clear patterns may result from the different species having evolved a variety of life history strategies, including life expectancies and age of maturity, and thus cannot be expected to respond in the same way to intensive fishing.

(3) Spatial ecology is important to understand the underlying mechanisms that drive fish population dynamics. Ciannelli et al. (2013) showed that spatial structure of a population can be modified by both climate and fishing, with consequences at the population and community levels. Ciannelli et al. (2013) advocated that the preservation of a population's spatial structure should be an explicit management goal, especially since spatial structures in marine populations are easier to monitor and characterize than demographic and genetic structures. Many commercially exploited stocks are surveyed multiple times in a year and over different life history stages. Therefore, there is already a large body of available information that can be integrated in management scenarios and that is less difficult or expensive to obtain than other data on population structures. However, the 'poor' data stocks (i.e. those stocks that are irregularly monitored or those not monitored at all because they are not commercially important) represent a challenge; these stocks will need to be monitored in order to reach the sustainable management objectives.

Acknowledgements. We thank the participants of the Tropharct workshops for their contributions, and the Research Council of Norway (RCN) for funding through the 
project MICO (Match/Mismatch and Ecosystem; no. 186310). G.O. and J.M.D. thank RCN for funding their contribution to this paper through the ADMAR (Adaptive management of living marine resources by integrating different data sources and key ecological processes, number 200497/130). We thank Mette Skern-Mauritzen, Lorenzo Ciannelli, Leif Chr. Stige and George Hunt for their comments on an early version of this paper.

\section{LITERATURE CITED}

Bacheler NM, Bailey KM, Ciannelli L, Bartolino V, Chan KS (2009) Density-dependent, landscape, and climate effects on spawning distribution of walleye pollock Theragra chalcogramma. Mar Ecol Prog Ser 391:1-12

Bakun A (2010) Linking climate to population variability in marine ecosystems characterized by non-simple dynamics: conceptual templates and schematic constructs. J Mar Syst 79:361-373

Bakun A, Weeks SJ (2006) Adverse feedback sequences in exploited marine systems: Are deliberate interruptive actions warranted? Fish Fish 7:316-333

Ciannelli L, Fisher JAD, Skern-Mauritzen M, Hunsicker ME, Hidalgo M, Frank KT, Bailey KM (2013) Theory, consequences and evidence of eroding population spatial structure in harvested marine fishes: a review. Mar Ecol Prog Ser 480:227-243

Durant JM, Hidalgo M, Rouyer T, Hjermann DØ and others (2013) Population growth across heterogeneous environments: effects of harvesting and age structure. Mar Ecol Prog Ser 480:277-287

Fauchald P (2010) Predator-prey reversal: a possible mechanism for ecosystem hysteresis in the North Sea? Ecology 91:2191-2197

Frank KT, Petrie B, Choi JS, Leggett WC (2005) Trophic cascades in a formerly cod-dominated ecosystem. Science 308:1621-1623
Gaston KJ, Blackburn TM, Greenwood JJD, Gregory RD, Quinn RM, Lawton JH (2000) Abundance-occupancy relationships. J Appl Ecol 37 (Suppl 1):39-59

Hilborn R, Walters CJ (1992) Quantitative fisheries stock assessment. Chapman \& Hall, New York, NY

Hjermann DØ, Fisher JAD, Rouyer T, Frank KT, Stenseth NC (2013) Spatial analysis of North Sea cod recruitment: concurrent effects of changes in spawning stock biomass, temperature and herring abundance. Mar Ecol Prog Ser 480:263-275

Houde ED (2008) Emerging from Hjort's Shadow. J Northwest Atl Fish Sci 41:53-70

Hsieh CH, Yamauchi A, Nakazawa T, Wang WF (2010) Fishing effects on age and spatial structures undermine population stability of fishes. Aquat Sci 72:165-178

Law R (2000) Fishing, selection, and phenotypic evolution. ICES J Mar Sci 57:659-668

Ottersen G, Stige LC, Durant JM, Chan KS, Rouyer TA, Drinkwater KF, Stenseth NC (2013) Temporal shifts in recruitment dynamics of North Atlantic fish stocks: effects of spawning stock and temperature. Mar Ecol Prog Ser 480:205-225

> Perry RI, Cury P, Brander K, Jennings S, Möllmann C, Planque B (2010) Sensitivity of marine systems to climate and fishing: concepts, issues and management responses. J Mar Syst 79:427-435

> Planque B, Fromentin JM, Cury P, Drinkwater KF, Jennings S, Perry RI, Kifani S (2010) How does fishing alter marine populations and ecosystems sensitivity to climate? J Mar Syst 79:403-417

Rouyer T, Ottersen G, Durant JM, Hidalgo M and others (2011) Shifting dynamic forces in fish stock fluctuations triggered by age truncation? Glob Change Biol 17: 3046-3057

Stige LC, Hunsicker ME, Bailey KM, Yaragina NA, Hunt GL Jr (2013) Predicting fish recruitment from juvenile abundance and environmental indices. Mar Ecol Prog Ser 480: 245-261 